\title{
A numerical model for pressure drop and flow distribution in a solar collector with U- connected absorber pipes
}

\author{
Bava, Federico; Furbo, Simon
}

Published in:

Solar Energy

Link to article, DOI:

10.1016/j.solener.2016.05.012

Publication date:

2016

Document Version

Peer reviewed version

Link back to DTU Orbit

Citation (APA):

Bava, F., \& Furbo, S. (2016). A numerical model for pressure drop and flow distribution in a solar collector with U-connected absorber pipes. Solar Energy, 134, 264-272. https://doi.org/10.1016/j.solener.2016.05.012

\section{General rights}

Copyright and moral rights for the publications made accessible in the public portal are retained by the authors and/or other copyright owners and it is a condition of accessing publications that users recognise and abide by the legal requirements associated with these rights.

- Users may download and print one copy of any publication from the public portal for the purpose of private study or research.

- You may not further distribute the material or use it for any profit-making activity or commercial gain

- You may freely distribute the URL identifying the publication in the public portal

If you believe that this document breaches copyright please contact us providing details, and we will remove access to the work immediately and investigate your claim 


\section{A numerical model for pressure drop and flow distribution in a solar 2 collector with U-connected absorber pipes}

\section{Federico Bava*, Simon Furbo}

4 DTU Civil Engineering, Technical University of Denmark, Brovej, Building 118, 2800 Kgs. Lyngby

5 (Denmark)

6 * Tel.: +45 45251700, Email: febav@byg.dtu.dk

\section{Abstract}

8 This study presents a numerical model calculating the pressure drop and flow distribution in a solar collector

9 with U-type harp configuration in isothermal conditions. The flow maldistribution in the absorber pipes, caused by the different hydraulic resistances, was considered to evaluate the pressure drop across the collector. The model was developed in Matlab and is based on correlations found in literature for both friction losses and local losses, and was compared in terms of overall pressure drop against experimental measurements carried out on an Arcon Sunmark HT 35/10 solar collector at different flow rates and temperatures for water and water/propylene glycol mixture. For collector pressure drops higher than $1.4 \mathrm{kPa}$, the relative difference between the model and measurements was within $5 \%$ for water and $7 \%$ for water/propylene glycol mixture. For lower pressure drops the relative difference increased, but remained within the accuracy of the differential pressure sensor. The flow distribution was mainly affected by the flow regime in the manifolds. Turbulent regime throughout the manifolds entailed a more uniform distribution across the absorber pipes compared to laminar regime. The comparison between calculated flow distributions and results from previous literature showed a good agreement.

Keywords: solar collector, U-configuration, pressure drop, flow distribution.

\section{Introduction}

The pressure drop over a solar collector should be known and taken into account, when connecting collectors in a solar collector field. In fact, the pressure drop impacts the flow distribution throughout the field, affecting the heat transfer rate in the collectors and hence their efficiency, and determines the requirements of the pumps that need to be installed to supply the field in the most efficient way.

The standard norm ISO 9806 does not strictly prescribe a specific fluid when performing the pressure drop test of a solar collector. It states that "the fluid used in the collector for the test shall be water or a mixture water/glycol (60/40), or a mixture recommended by the manufacturer. The temperature of the fluid shall be (20 \pm 2$)^{\circ} \mathrm{C}$ ” (ISO 9806). Therefore, if different fluids are used to test different collectors, the test results cannot be directly compared (Kovacs et al., 2012). Additionally, the conditions during the test may differ significantly from the actual operating conditions of the collector, both in terms of fluid type and operating temperature. For this reason, it could be useful to have a model able to derive the pressure drop of a collector for different temperatures and fluids, starting from a single test carried out in a specific operating condition. connecting two manifolds. This configuration allows a high ratio between pipe length and absorber area, without too large pressure drops. On the other hand, the parallel pipe design has the disadvantage of nonuniform flow distribution in the different parallel pipes. The flow distribution in flat plate collectors with parallel pipes has been the topic of many investigations, as it may strongly affect the collector efficiency. In fact, several studies show that the efficiency decreases for higher flow maldistribution, as a consequence of non-uniform outlet temperatures for the different collector pipes. Chiou (1982) developed a method to determine how much the collector efficiency is deteriorated by flow maldistribution, but he did not calculate the flow distributions himself. He defines a flow nonuniformity parameter as the root mean square deviation of the absorber pipe flow rates and concludes that the deterioration of the collector efficiency is proportional to approximately the square of such parameter. Wang and Wu (1990) propose a discrete numerical model to predict the flow and temperature distribution in collector arrays with vertical pipes, both in U-type and Z- 
type configuration, taking into account buoyancy force. The U-type array presents a higher maldistribution and hence its efficiency is more penalized compared to the Z-type array. The flow rate in the absorber pipes for the U-type array decreases monotonically with the distance from the manifold inlet. The same trend is found by Jones and Lior (1994), who considered a single collector with vertical pipes, instead of an entire array, and neglected buoyancy effect. The flow is assumed isothermal, as buoyancy and temperature dependence of the thermophysical properties are expected to play a negligible role, as argued in the authors' previous work (Jones and Lior, 1987). Weitbrecht et al. (2002) carried out both an experimental and analytical study on the flow distribution in a Z-type collector in isothermal conditions. They investigated the influence that the inset of a pipe into the manifold has on the pressure drop across the tee junction. However, only laminar flow and one specific tee geometry were considered. Still, the effort of investigating pressure drops in tees with inset is noteworthy. In fact, the pipe inset is often neglected or simplified in other studies, but can play a role in the flow distribution by increasing significantly the pressure drop compared to tees with sharp edges (Ohnewein et al., 2015).

Fan et al. (2007) studied the flow and temperature distribution in a large solar collector with 16 U-connected horizontal tubes with quadrilateral cross section. A numerical model, based on CFD calculations and taking into account buoyancy, and experimental measurements are compared. The results show that the flow distribution is dominated by friction (and hence buoyancy can be neglected), if the velocity in the collector pipes is high compared to the temperature rise across the collector. In large solar collector fields in Denmark each row usually consists of 10 to 25 collectors (Windeleff and Nielsen, 2014), so the temperature rise in each collector is relatively small, while the flow rate is relatively high. Consequently, it can be considered that buoyancy plays a minor role in the flow distribution in this kind of installations. As the focus of the present study was on large solar collectors for collector field applications, the assumption of no buoyancy was made and the flow was assumed isothermal.

The aim of the study was to develop a numerical model for calculating the pressure drop and flow distribution in a U-type harp collector under isothermal conditions. The model, whose source code is publicly available online (Bava, 2015) and can be easily customized by other users, takes only a couple of seconds to perform a simulation. The model is based on a very common design of solar collector, so it can be used to evaluate geometry improvements to achieve more uniform flow distribution. Both laminar and turbulent regimes were considered, and an effort was made to take into account the effect of the pipe inset into the manifolds. The reliability of the model was verified by comparing its results against experimental measurements and previous literature findings.

\section{Material and method}

\subsection{Numerical model}

\subsubsection{Pressure drop correlations}

81 In a solar collector, as well as in any other hydraulic circuit, the total pressure drop is given by the sum of two types of pressure losses: friction (or major) losses and local (or minor) losses. Friction losses occur in pipe flow because of viscous effects generated by the pipe surface. Local losses are due to variations of momentum. Valves, bends, tees and abrupt changes in pipe cross section are examples of components causing local pressure losses.

86 The friction loss along a straight pipe of constant cross section can be calculated by the Darcy-Weisbach 87 equation:

$$
\Delta p=\lambda \frac{l}{D_{h}} \frac{\rho w^{2}}{2}
$$

where $\Delta p$ is the pressure drop [Pa], 
$\rho$ is the fluid density $\left[\mathrm{kg} \mathrm{m}^{-3}\right]$,

$w$ is the mean fluid velocity $\left[\mathrm{m} \mathrm{s}^{-1}\right]$.

The friction factor depends on the type of flow regime and, if this is turbulent, on the roughness of the pipe as well. The parameter indicating whether a flow is laminar or turbulent is the Reynolds number, defined as

$$
R e=\frac{w \rho D_{h}}{\mu}
$$

where $\quad R e$ is the Reynolds number [-],

$$
\mu \text { is the fluid dynamic viscosity [Pa s]. }
$$

Density and viscosity are properties characteristic of each fluid and are dependent on the temperature. Water and propylene glycol/water mixtures are the most common fluids used in solar thermal applications.

Thermophysical properties of water are well known and are easily found in literature. For the density, the correlation (eq.3) proposed by Furbo (2015) was used, while the dynamic viscosity was evaluated through equation (eq.4) proposed by Kestin (1978):

$$
\begin{aligned}
\rho=1000.6-0.0128 T^{1.76} \\
\begin{aligned}
\log \left\{\mu(T) / \mu\left(T=20{ }^{\circ} \mathrm{C}\right)\right\}= & \left\{1.2378-1.303 \cdot 10^{-3} \cdot(20-T)+3.06 \cdot 10^{-6} \cdot(20-T)^{2}+\right. \\
& \left.+2.55 \cdot 10^{-8} \cdot(20-T)^{3}\right\} \cdot(20-T) /(T+96)
\end{aligned}
\end{aligned}
$$

where $T$ is the fluid temperature $\left[{ }^{\circ} \mathrm{C}\right]$.

Given the large variability of the properties of propylene glycol/water mixtures found in literature and in product datasheets, these were experimentally determined with an Anton Paar DMA 4100 densimeter and an Anton Paar AMV 200 viscometer. Three samples with glycol concentration of $40 \%, 45 \%$ and 50\% were tested at temperatures between $20^{\circ} \mathrm{C}$ to $80^{\circ} \mathrm{C}$ with an intermediate step of $10^{\circ} \mathrm{C}$. The experimental data points were then interpolated with the polynomial expressions (eq.5) and (eq.6):

$$
\begin{aligned}
& \rho=1013-0.2682 T+0.7225 x-1.94 \cdot 10^{-3} T^{2}-4.964 \cdot 10^{-3} \times T \\
& \mu=\left(-2.881-6.721 \cdot 10^{-3} T+0.2839 x+1.959 \cdot 10^{-3} T^{2}+\right. \\
&\left.-7.036 \cdot 10^{-3} \times T-1.883 \cdot 10^{-5} T^{3}+4.862 \cdot 10^{-5} \times T^{2}\right) \cdot 10^{-3}
\end{aligned}
$$

where $x$ is the mass concentration of propylene glycol in the mixture [\%].

Laminar flow regime is characterized by low values of Reynolds number. In literature it is often stated that, for fully developed flow in a circular pipe, laminar flow occurs for $R e<2300$, and turbulent flow for $R e>4000$ (Holman, 2002). The flow regime between laminar and turbulent is referred to as transitional regime. In reality, the exact value at which change in flow regime occurs is extremely difficult to determine and depends on whether small disturbances are present. In the developed model, the flow was assumed laminar for $R e<2300$, and turbulent for $R e>3100$, as a result of a series of tests carried out to evaluate transition in flow regime in the HT collector pipes. More detailed information about how these tests were performed and analyzed is reported in Appendix.

In case of laminar flow, the Darcy friction factor was calculated through the Hagen-Poiseuille law:

$$
\lambda=64 / R e
$$

For turbulent flow the Blasius correlation for smooth pipes (eq.8) was used, as the collector manifolds and pipes were made of commercial copper tubes, characterized by very small absolute roughness (Binder, 1973).

$$
\lambda=0.3164 / R e^{0.25} \quad(\text { eq.8) }
$$

Beside the Blasius correlation, other friction factor correlations were implemented in the model, such as those proposed by Colebrook (1939) and Haaland (1983) for turbulent flow in pipes of known roughness, and by Joseph and Yang (2010) for any flow regime in smooth pipes.

Following the example of Jones and Lior (1994), the friction factor in the transition region $(2300<\operatorname{Re}<3100)$ was calculated by linear interpolation between the value obtained from (eq.7) for $R e=2300$ and that obtained 
138 Regarding local losses, in the solar collector under investigation the only discontinuities were represented by

139 the tees connecting the absorber pipes to the manifolds. The correlations used to model the pressure losses in 140 tees were mainly obtained by Idelchik (1994). For the sake of simplicity, these correlations are not reported 141 here, but can be found as part of the code of the developed model (Bava, 2015). Though, Idelchik's 142 correlations refer to tees with sharp edges and without any inset, while the collector under investigation had

$143 \quad 2-3 \mathrm{~mm}$ inset of the absorber pipes into the manifold. As even short insets have been proven to be able to

144 affect the pressure drop across tees (Ohnewein et al., 2015), Idelchik's correlations were corrected based on

145 the results from Ohnewein et al. (2015). In Ohnewein et al. (2015) Figures 33-38 present the measured

146 pressure drop coefficients in different types of tee junctions for different inset lengths and different flow rate ratios between side passage and combined passage of the tee junction. In the same diagrams also Idelchik's pressure drop coefficients for turbulent conditions are reported, even when the Reynolds number in the combined passage of the tee junction is very low (for example $R e=500$ in Figure 37). For this reason, in order to make a fair comparison, the coefficients proposed by Ohnewein et al. were compared to those from Idelchik, using turbulent or laminar correlations accordingly. Among the different pressure drop coefficients proposed by Ohnewein et al., those with an inset length/manifold diameter ratio closer to that of the investigated collector (see Section 2.2) were chosen. Based on the comparison, the following conclusions were drawn:

- good agreement was found between Ohnewein et al.’s and Idelchik's pressure drop coefficients in case of straight passage in a diverging tee junction both in laminar and turbulent conditions;

- good agreement was found in case of side passage in a diverging tee junction in laminar conditions, assuming that at $R e=3500$ in the combined passage of the tee junction the flow is still laminar;

- in case of side passage of a diverging tee junction in turbulent conditions, Ohnewein et al. measured pressure drop coefficients about 0.75 times those predicted by Idelchik;

- in case of straight passage of a combining tee junction in turbulent conditions, Ohnewein et al. measured pressure drop coefficients about 2.2 times higher than those predicted by Idelchik.

Hence, Idelchik's correlations were corrected accordingly and implemented in the model. Given the collector geometry, the above mentioned pressure drop coefficients for isolated tee junctions could be used to evaluate the pressure losses along the manifolds, which, according to Miller (2009), is allowed when the distance between two consecutives tees is three times longer than the manifold diameter.

\subsubsection{Matlab implementation}

168 Using the pressure drop correlations described in the previous section, a numerical model was developed in 169 Matlab to compute the flow distribution and the resulting pressure drop across a collector. The input data to 170 the model are the dimensions of the collector hydraulics and operating conditions of the heat transfer fluid 171 (glycol content, flow rate and fluid temperature). The fluid temperature, which is assumed to be constant 172 throughout the collector, is used to determine the density and viscosity of the fluid. Additionally, the flow is 173 considered to be fully developed.

174 Given an initial flow rate as input, the model assumes that the flow is uniformly distributed in all absorber 175 pipes. A uniform flow distribution would cause the pressure drop to increase from one strip to the next (see 176 strip numbering in Figure 1), as the fluid path becomes longer due to additional manifold segments. In 177 reality, the pressure drop must be the same, irrespective of the path the fluid follows, resulting in an 178 adjustment of the flow rate in each absorber pipe. In order to calculate the true flow distribution, the 179 numerical model solves iteratively the set of equations (eq.9), which impose both the conservation of mass 180 across the collector (first line in (eq.9)) and the uniformity of pressure drop along the different hydraulic 181 paths (from second line downward in (eq.9)):

$$
\left(\begin{array}{cccccc}
1 & 1 & 1 & 1 & 1 & 1 \\
k_{1, j} \cdot \dot{m}_{1, j} & -k_{2, j} \cdot \dot{m}_{2, j} & 0 & 0 & 0 & 0 \\
0 & k_{2, j} \cdot \dot{m}_{2, j} & -k_{3, j} \cdot \dot{m}_{3, j} & 0 & 0 & 0 \\
\vdots & \vdots & \vdots & \vdots & \vdots & \vdots \\
0 & 0 & 0 & 0 & k_{N-1, j} \cdot \dot{m}_{N-1, j} & -k_{N, j} \cdot \dot{m}_{N, j}
\end{array}\right)\left(\begin{array}{c}
\dot{m}_{1, j+1} \\
\dot{m}_{2, j+1} \\
\dot{m}_{3, j+1} \\
\vdots \\
\dot{m}_{N, j+1}
\end{array}\right)=\left(\begin{array}{c}
\dot{m}_{t o t} \\
0 \\
0 \\
\vdots \\
0
\end{array}\right)
$$


where $\dot{m}$ is the mass flow rate $\left[\mathrm{kg} \mathrm{s}^{-1}\right.$,

$k$ is a hydraulic resistance coefficient $\left[\mathrm{kg}^{-1} \mathrm{~m}^{-1}\right]$, defined so that the product $\left(k_{i} \cdot \dot{m}_{i}{ }^{2}\right)$ corresponds to the pressure drop (in Pascal) across the $i$-th hydraulic path. The factor $k_{i}$ is representative of the pressure drop along the $i$-th absorber pipe, which is proportional to the square of the flow rate $\dot{m}_{i}$, as well as the pressure drop across the manifold segments and tees included in the $i$-th hydraulic path, properly normalized to the flow rate $\dot{m}_{i}$,

$1,2, \ldots, N$ subscripts denote the hydraulic path and $N$ is the total number of hydraulic paths,

tot subscript refers to the total flow rate supplied to the collector,

$j$ subscript denotes the iteration number.

The iterative procedure is continued until the difference in the absorber pipe flow rates between two consecutive iterations is lower than $0.1 \%$. With this convergence constraint a typical calculation is performed in a couple of seconds for a computer with quad-core CPU, 2.4 GHz CPU frequency and 8 GB memory.

The entire Matlab code used to carry out the present study is publicly available online (Bava, 2015).

\subsection{Experimental setup for pressure drop measurement}

The developed model was based on the design of U-type large scale collectors. These collectors have a number of horizontal absorber pipes welded to absorber strips and connecting two vertical manifolds located along the sides of the collector with their outlet at the top corners (Figure 1).

The selection of this design was motivated by the fact that this is the most frequently adopted when manufacturing large collectors for solar heating field applications. In fact, these collectors are easy to assemble and quick to connect to one another when installed side by side in a field.

Figure 1: Sketch of a U-type absorber with horizontal absorber pipes (adapted from Fan et al., 2007).

To validate the model in terms of overall collector pressure drop, the results were compared to measurements carried out on a large scale collector in different operating conditions. The tested collector was an Arcon Sunmark HT-SA 35/10 module, having an aperture area of $12.60 \mathrm{~m}^{2}$. The collector piping was made of copper and had circular cross sections. The 18 absorber pipes were $5.80 \mathrm{~m}$ long, had an inner diameter of 9.1 $\mathrm{mm}$ and an intermediate spacing of $122 \mathrm{~mm}$. The manifolds had an inner diameter of $32.9 \mathrm{~mm}$.

A differential pressure sensor TA-SCOPE from IMI Hydronics was used to measure the pressure drop across the collector. The instrument nominal accuracy is given by the higher value between $0.1 \mathrm{kPa}$ and $1 \%$ of the measured value.

The volume flow rate supplied to the collector was measured by a Kamstrup MP115 electromagnetic flow meter. Its accuracy is stated to be within $\pm 0.50 \%$. Additionally, the instrument was calibrated with water and propylene glycol/water mixture at different fluid temperatures and flow rates, and its nameplate calibration factor was confirmed.

Transparent plastic tubes were connected to the inlet and outlet of the collector at one end and to the pressure sensor at the other end, as shown in Figure 2. The transparent pipes made it easier to verify that no air was present in the circuit, which otherwise would alter both the flow rate and differential pressure measurements. As the plastic pipes could not be connected exactly at the inlet and outlet of the solar collector (Figure 3), the pressure losses occurring in between needed to be evaluated, in order not to assign them to the collector.

\footnotetext{
Figure 2: Back of the HT-SA 35/10 solar collector with plastic pipes arrangement for pressure drop measurement.
}

Figure 3: Detail of collector outlet with connection for the differential pressure sensor.

Fluid temperature was measured both at the inlet and outlet of the collector by type $\mathrm{T}$ thermocouples (copper/constantan junction).

Pressure drop measurements were carried out for flow rates between 0.08 and 0.72 liters s-1 $\left(0.3-2.6 \mathrm{~m}^{3} \mathrm{~h}^{-1}\right)$ and at temperatures of approximately $25^{\circ} \mathrm{C}, 55^{\circ} \mathrm{C}$ and $70^{\circ} \mathrm{C}$, with water and a $50 \%$ propylene glycol/water mixture as heat transfer fluid. The tests were performed in cloudy sky conditions, so that the temperature rise across the collector was negligible and the assumption of isothermal flow introduced in the model was 
fulfilled.

230

231

232

233

234

235

236

237

238

239

240

241

242

243

244

245

246

247

248

249

250

251

252

253

254

255

256

257

258

259

260

261

262

263

264

265

266

267

268

269

270

271

272

273

274

275

\section{Results}

\subsection{Collector pressure drop}

The comparison between the measured and calculated pressure drops as function of the flow rate is shown in Figure 4 and Figure 5. Given the configuration of the hydraulic circuit, it was possible to test volume flow rates up to $2.6 \mathrm{~m}^{3} \mathrm{~h}^{-1}$, corresponding to pressure drops of approximately 9-10 $\mathrm{kPa}$. The lower boundary of the tested flow rate was determined by the error of the differential pressure sensor, which became increasingly predominant when measuring pressure drops lower than $1 \mathrm{kPa}$. The error bars for the measured pressure drops represent the maximum value between the accuracy of the differential pressure sensor (i.e. the higher value between $0.1 \mathrm{kPa}$ and $1 \%$ of the measured value) and the standard deviation of the measured values. For sake of simplicity of the diagrams, the error bars relative to the measured flow rates are not shown, as they are much smaller compared to the uncertainty of the differential pressure measurements. In fact, for all tested flow rates, the highest of the ratios between standard deviation and mean value was $0.43 \%$, and most of them were lower than $0.20 \%$. Consequently, they were always lower than the nameplate accuracy of the flow meter $( \pm 0.50 \%)$ and more than twice as small as the accuracy of the differential pressure sensor.

Figure 4: Comparison between measured and calculated pressure drops for water.

Figure 5: Comparison between measured and calculated pressure drops for 50\% propylene glycol/water mixture.

The pressure drop values given by the model matched the measured values with a reasonable accuracy. For values higher than $1 \mathrm{kPa}$, the highest relative difference between model and measurements was equal to $5 \%$ for water. Regarding the glycol/water mixture, the highest relative difference was $10 \%$ for a measured pressure drop of $1.37 \mathrm{kPa}$, while in the other cases it was within $7 \%$.

For values lower than $1 \mathrm{kPa}$, the relative differences were slightly higher. The highest deviation (15\%) was found for the lowest pressure drop $(0.2 \mathrm{kPa})$. However, this deviation was within the accuracy range of the differential pressure sensor $(0.1 \mathrm{kPa})$. Apart from this, no particular trend of discrepancy could be identified with respect to flow rate, temperature or fluid type, as both positive and negative deviations are found (see Figure 4 and Figure 5). Figure 4 shows that for water at high flow rates $\left(V \geq 1.5 \mathrm{~m}^{3} \mathrm{~h}^{-1}\right.$ at $25^{\circ} \mathrm{C}$ and $V \geq 2.0 \mathrm{~m}^{3}$ $\mathrm{h}^{-1}$ for at $55^{\circ} \mathrm{C}$ and $70{ }^{\circ} \mathrm{C}$ ) the model underestimated the actual pressure drop by $3 \%-5 \%$. An underestimation of the friction factor in the corresponding range of Reynolds number $\left(R e_{\text {pipe }}>5200\right)$ was at first assumed as possible cause of these deviations. However, other data points in the same range of Reynolds number did not show similar deviations. Additionally, in order to increase the friction factor for this range of Reynolds number in such a way that these deviations were minimized, the roughness of copper pipes should have been assumed 10 times higher than that usually reported in literature (Binder, 1973). Such a correction did not seem acceptable, also based on the results of some surface roughness tests carried out on similar collector pipes. Hence, the assumption of smooth pipes was maintained.

Beside the accuracy of the instruments, other sources of error might be the assumptions made in the model, such as linear interpolation between laminar and turbulent conditions in case of transitional regime and fully developed flow throughout the pipes.

In both diagrams, the typical quadratic relation between pressure drop and flow rate can be observed, as the different groups of points are approximately aligned along parabolic trajectories. Additionally, the influence of the fluid temperature on the pressure drop across the collector can be noted by comparing the different series of points within the same diagram. As expected, a fluid flow at lower temperature caused a higher pressure drop for the same flow rate.

\subsection{Flow distribution}

The flow distribution was expressed in terms of dimensionless flow rate in the absorber pipes, defined by (eq.10) as:

$$
V_{i}^{\prime}=\frac{V_{i}}{\left(\sum_{i=1}^{N} V_{i}\right) / N}
$$

where $\quad V_{i}^{\prime}$ is the dimensionless flow rate flowing in the $i$-th absorber pipe [-], 
$N$ is the number of absorber pipes [-].

\subsubsection{Comparison with previous literature}

As no validation in terms of flow distribution could be performed in the test rig, the model results were compared with data found in literature. Results from the simulation model of Jones and Lior (1994) were chosen for comparison, because of the similarity in collector design as well as the identical assumption of isothermal flow. In Jones and Lior's paper, model results obtained for a U-type harp collector having 8 or 16 absorber pipes are presented. The absorber pipes are $1.83 \mathrm{~m}$ long and can have a diameter of $0.25,0.50$ and 0.75 times the manifold diameter, which is $2.54 \mathrm{~cm}$. The manifolds length is $0.915 \mathrm{~m}$. As heat transfer fluid water at $60{ }^{\circ} \mathrm{C}$ is assumed and the flow rate is varied in such a way that the Reynolds number at the manifold inlet is 3210, 9640 and 16100 in different cases. Darcy friction factors are evaluated using Colebrook equation (Colebrook, 1939) for $R e>3000$ and Hagen-Poiseuille law (eq.7) for $R e<2100$. Linear interpolation between the two is used for the transition regime. The roughness of the pipe material is not specified in the paper, but it is said to be intermediate between that for clean copper and steel. A value of $0.016 \mathrm{~mm}$ was therefore selected in the model proposed in the present paper. Regarding tee junctions, the schemes reported by Jones and Lior imply that sharp edge tees were considered. The pressure change across the tee junctions is evaluated based on momentum conservation and constant pressure regain coefficients ( $\gamma=0$ for converging tee junction and $\gamma=0.9$ for diverging tee), with no distinction between laminar and turbulent regime. Additionally, the energy loss coefficient at the entrance and exit of the absorber pipes is assumed to be constant and equal to 1.2. The last two assumptions may not be very accurate, as pressure drops in tees are shown to be very sensitive to the tee geometry and flow characteristics (Idelchik, 1994; Ohnewein et al., 2015). However, to make the comparison between the two models fair, the same assumption was made in the proposed model and the pressure drop correlations for tees in turbulent regime were used also in the laminar region.

The comparison between the flow distributions found by Jones and Lior and those given by the proposed model are shown in Figure 6 for two different cases. The first refers to a collector with 8 pipes and a ratio between pipe and manifold diameters of 0.50 . The second case refers to a collector with 16 pipes and a diameters ratio of 0.25 . This resembles more closely the geometry of a large scale collector on which the present model was based. In both cases the Reynolds number at the manifold inlet was 9640 .

Figure 6: Comparison in flow distribution between Jones and Lior's model and the proposed model.

In Figure 6 it can be seen that the two couples of profiles presented a very similar trend, with the presented model predicting a more uniform flow distribution compared to Jones and Lior's. The difference was relatively small, with maximum deviations of $5 \%$ and $1 \%$ in case of 8 and 16 pipes respectively, and it was most likely due to the different correlations used to estimate the energy losses in the tee junctions.

Another difference between the two models was the trend of the curves in the bottom pipes. Due to the assumption made by Jones and Lior about the constant pressure regain coefficients, the profiles returned by their model were strictly decreasing. On the other hand, the pressure drop coefficients from Idelchick (1994) used in the proposed model allowed a slight increase in flow in the last pipes, as shown in the case with $N=8$ in Figure 6. This happened because the pressure drop across the side passage of diverging tee junctions decreased with the reduction in the manifold flow rate more significantly than the increase in hydraulic resistance given by the other hydraulic components (tee junctions and manifold segments).

A good agreement between the two models was found for most of the other combinations of Reynolds number and diameters ratio proposed by Jones and Lior in their paper, with maximum deviations of $5 \%$. Exceptions were the results obtained for a diameters ratio of 0.75 . In this case, Jones and Lior's model predicted a much stronger non-uniformity, with the top pipe having a flow rate up to four times higher than in the bottom pipe. In the same conditions, the proposed model predicted a ratio between of the two flow rates of approximately two. The difference between the models was caused by the different correlations used to evaluate the pressure drops in the tee junctions. In case of a large diameters ratio, the pressure drop across the absorber pipes is not predominant any more, and the pressure drops across the tee junctions play a more important role in determining the flow distribution. 
Using the developed model, it was possible to calculate the flow distribution inside the HT 35/10 collector at different flow rates and fluid types. Two cases were considered, one with water at $70{ }^{\circ} \mathrm{C}$ (Figure 7) and the other with water at $20^{\circ} \mathrm{C}$ (Figure 8). Due to the different fluid viscosity at different temperatures, these two cases allowed to study the flow distribution at similar flow rates, but in different flow regimes.

331 The flow distributions shown in Figure 7 and Figure 8 decrease from the top to the bottom pipe, but with different profiles. In case of water at $70{ }^{\circ} \mathrm{C}$ (Figure 7), the distribution was more uniform, especially at flow rates higher or equal to $1.5 \mathrm{~m}^{3} \mathrm{~h}^{-1}$, for which the parameter $V^{\prime}$ ranged from 0.92 to 1.09 . At these flow rates the flow across the absorber pipes and in the largest part of the manifold was turbulent. At a flow rate of 0.7 $\mathrm{m}^{3} \mathrm{~h}^{-1}$, the flow regime in the manifold was turbulent in the first 15 pipes and consequently the flow distribution was still roughly uniform. Conversely, in the last three manifold segments the flow regime switched to laminar, causing a stronger decrease of the flow rates in the last absorber pipes and a wider spread of the $V^{\prime}$ values.

Figure 7: Flow distribution in the absorber pipes at different flow rates for water at $70{ }^{\circ} \mathrm{C}$.

Figure 8: Flow distribution in the absorber pipes at different flow rates for water at $20{ }^{\circ} \mathrm{C}$.

In case of water at $20^{\circ} \mathrm{C}$ (Figure 8), the laminar regime in the pipes and most of the manifolds caused a much less uniform flow distribution. This is particularly evident at the lower flow rates of 0.5 and $1 \mathrm{~m}^{3} \mathrm{~h}^{-1}$, where $V^{\prime}$ varied more strongly, in a range between 0.66 and 1.25 . For higher flow rates the portion of manifolds experiencing turbulent conditions increased and the flow distribution became more uniform, similar to the profiles shown in Figure 7.

Through the developed model, it was also possible to study the contribution to the total pressure drop of the single hydraulic components, such as absorber pipes, manifolds and tee junctions. Although the pressure drop across the absorber pipes played the most significant role in both cases, its importance for the different paths was quite different, depending on the flow regime. In case of turbulent regime in all absorber pipes, the pressure drop along these represented $86 \%-90 \%$ of the total collector pressure drop for the top pipe, and $66 \%-71 \%$ for the bottom pipe. The remaining part was caused by forward and return manifolds as well as tee junctions. In case of laminar regime, the pressure drop in the absorber pipe was $87 \%-92 \%$ of the total for the top pipe, and $44 \%-50 \%$ for the bottom pipe.

\section{4}

355

356

357

358

359

360

361

362

363

364

365

366

367

368

369

370

371

372

\section{Discussion}

\subsection{Pressure drop}

As expected, when testing the two heat transfer fluids at the same temperature and flow rate, the pressure drop for the glycol/water mixture was larger than for water, because of the much higher viscosity. For the same reason, the pressure drop for both fluids was higher at lower temperatures. Nevertheless, this effect was much more relevant for the $50 \%$ glycol/water mixture than for water. This was due to two main factors. Firstly, the kinematic viscosity of water decreases by a factor of 2.7 when the temperatures increases from 20 ${ }^{\circ} \mathrm{C}$ to $80^{\circ} \mathrm{C}$, while that of a $50 \%$ glycol/water mixture decreases by a factor of 5 for the same temperature variation. Secondly and more importantly, the higher viscosity of the glycol/water mixture at about $20^{\circ} \mathrm{C}$ caused the flow regime in the absorber pipes to be laminar, even at the highest tested flow rate of $2.5 \mathrm{~m}^{3} \mathrm{~h}^{-1}$. This entailed much higher friction factors compared to those obtained at higher temperatures.

Despite its secondary importance, the higher density also contributed in increasing the pressure drop at lower temperatures. The effect was more important for the glycol/water mixture, as its density varies by about $4 \%$ in the range $20^{\circ} \mathrm{C}-80{ }^{\circ} \mathrm{C}$, compared to $2 \%$ for water.

It can also be noted that the pressure drop for glycol/water mixture at $70^{\circ} \mathrm{C}$ was very similar to that of pure water at $20^{\circ} \mathrm{C}$. This was due to the fact that the two fluids have very similar kinematic viscosity and density in these conditions $\left(v \approx 1 \cdot 10^{-6} \mathrm{~m}^{2} \mathrm{~s}^{-1}, \rho \approx 1000 \mathrm{~kg} \mathrm{~m}^{-3}\right)$. This means that the pressure drop curves for glycol/water mixtures at relatively high temperature may be indirectly evaluated using water at sufficiently low temperature.

\subsection{Flow distribution}


The results given by the model showed a decrease in flow rate from the top to the bottom pipes, because only friction was considered as driving force, so that the longer the hydraulic path, the higher the resistance. This

376 is in agreement with the findings of Wang and Wu (1990), Jones and Lior (1994) and Fan et al. (2007).

377 A large difference appeared to exist when comparing flow distributions characterized by a different flow 378 regime. Turbulent flow in the manifolds entailed relatively small pressure losses both in manifold segments 379 and tees, compared to those occurring across the absorber pipes. So, these additional pressure drops could be 380 compensated by a slight unbalance in the collector flow distribution. This is shown in Figure 7 by the flow 381 distributions referring to the flow rates of 2.5 and $3.5 \mathrm{~m}^{3} \mathrm{~h}^{-1}$. The extent of the unbalance in flow distribution, 382 which was needed to compensate the pressure drop caused by manifolds segments and tees, was also affected 383 by the flow regime in the absorber pipes. Due to the geometry of the HT 35/10 collector, the flow regime in 384 all absorber pipes was turbulent, when it was turbulent in the entire manifold. Given the weak dependence of 385 the friction factor in the turbulent region on the Reynolds number (see (eq.8)), the friction pressure drop in 386 the absorber pipes can be considered proportional to the square of the fluid velocity, so that small variations 387 in flow rate cause larger variations in pressure drop. For this reason, a slight unbalance in flow distribution is 388 sufficient to give the right pressure drop along each hydraulic path.

389 Figure 7 also shows that when turbulent regime was established throughout the collector, then the flow 390 distribution was not significantly affected by the total flow rate, which is in agreement with previous findings 391 (Jones and Lior, 1994).

392 At lower flow rates $\left(V \leq 1.5 \mathrm{~m}^{3} \mathrm{~h}^{-1}\right.$ in Figure 7$)$, only part of the manifolds was in turbulent conditions, so that 393 laminar equations applied to the last manifold segments and tees. As both pressure drop coefficients for tees 394 and friction factor coefficients are much higher in laminar regime than in turbulent regime, the flow rate in 395 the last absorber pipes needed to diminish abruptly in order to cause the same pressure drop as the previous 396 hydraulic paths, causing a higher flow non-uniformity.

397 On the other hand, when using water at $20^{\circ} \mathrm{C}$ (Figure 8), the higher viscosity resulted into laminar regime in 398 the absorber pipes and in larger part of the manifolds. At lower flow rates $\left(V \leq 1 \mathrm{~m}^{3} \mathrm{~h}^{-1}\right)$, the flow regime in all 399 absorber pipes was laminar, while it was initially turbulent in the manifold and then, as more fluid was 400 diverted to the absorber pipes, laminar. The precise tee junction after which the change in flow regime 401 occurred can be identified looking at the change in slope in the curves in Figure 8: a milder slope 402 corresponds to turbulent flow in the manifold, while a steeper slope to laminar flow. The flow distribution at 403 these flow rates was much less uniform than in the turbulent case (Figure 7). The main reason for this 404 behavior was that the local loss coefficients for tees in laminar regime are more sensitive to flow conditions 405 than in turbulent regime, so they varied more significantly from one pipe to the next. As the hydraulic 406 resistance between two consecutive pipes differed more significantly, this needed to be compensated by a 407 larger difference in flow rates. A secondary reason is the linear dependence of the friction pressure drop on 408 the fluid velocity in laminar conditions (see (eq.1) and (eq.7)), which, compared to the quadratic dependence 409 in turbulent conditions, required larger variations in flow rate to compensate the varying pressure drop across 410 the absorber pipes.

411 The distribution became more uniform at higher flow rates, as a longer part of the manifolds experienced 412 turbulent conditions and the regime inside the absorber pipes became transitional $\left(V=1.5 \mathrm{~m}^{3} \mathrm{~h}^{-1}\right)$ and then 413 turbulent $\left(V=2 \mathrm{~m}^{3} \mathrm{~h}^{-1}\right)$.

414 The fact that the modeled flow distributions become more uniform at higher flow rates seems to be in 415 disagreement with previous literature. For example, Jones and Lior (1994) show that the flow distribution in 416 a harp collector (both in Z- and U-configuration) is approximately independent of the Reynolds number at 417 the manifold inlet, and hence of the total flow rate. Only for the highest ratio between absorber pipe and 418 manifold diameters $(d / D=0.75)$, the flow distribution at the lowest flow rate $\left(R e_{\text {inlet }}=3210\right)$ was slightly more 419 uniform than at higher flow rates $\left(R e_{\text {inlet }}=9640\right.$ and $\left.R e_{\text {inlet }}=16100\right)$. The reason for the different trend found 420 through the proposed model was mainly the use of different correlations for tee junctions, depending on the 421 flow regime. As an example, Figure 9 shows the modeled flow distributions in a HT-SA 35/10 collector at 422 different manifold inlet Reynolds numbers, using turbulent correlations for tee junctions regardless of the 423 actual flow regime. In this case the trend of the flow distributions was in agreement with Jones and Lior 424 (1994). However, given the good agreement between the measurements from Ohnewein et al. at low 
Reynolds number and Idelchik's laminar correlations, it was decided to keep the latter in the model.

Figure 9: Flow distribution in the absorber pipes of a HT-SA 35/10 collector for different manifold inlet Reynolds numbers.

427 As mentioned, isothermal flow was assumed in the model. In real operating conditions, the temperature of

428 the heat transfer fluid would increase along the absorber pipes. If the temperature rise is relatively small, the

429 fluid properties do not change significantly and using the mean fluid temperature is an acceptable

430 simplification. Nevertheless, in case of uneven flow distribution and uniform solar irradiance on the

431 collector, a pipe with a lower flow would experience a larger temperature rise and a higher mean fluid

432 temperature. The fluid viscosity would be lower, and thereby the friction factor and hydraulic resistance

433 would be smaller. Consequently, the flow distribution in case of non-isothermal conditions would partly

434 balance itself, resulting in a more uniform distribution compared to isothermal conditions. The effect is

435 expected to be more relevant in case of laminar flow, because of the stronger flow maldistribution (Figure 8)

436 and the direct proportionality between friction factor and fluid viscosity (see (eq.2) and (eq.7)).

437 Flow maldistribution in a harp collector causes a decrease in the collector efficiency. In fact, absorber pipes

438 having lower flow rates and hence higher temperatures suffer higher heat losses. The warmer fluid at the exit

439 of these pipes is tempered down by the colder fluid coming from the absorber pipes supplied with higher

440 flow rates. The mixing of flows at different temperatures causes a lower temperature rise across the collector

441 compared to the case with uniform flow distribution and identical temperature rise across each absorber pipe.

442 Consequently, the overall collector efficiency decreases. The negative effect of the flow maldistribution on

443 the collector efficiency is increased primarily by the degree of maldistribution and secondly by the collector

444 heat loss coefficient. The quantitative relationship between flow maldistribution and collector efficiency

445 degradation is out of the scope of this investigation. However, an estimation of this effect can be found in

446 Chiou (1982). In fact, defined a flow nonuniformity parameter as the root mean square deviation of the

447 absorber pipe flow rates, the deterioration of the collector efficiency is expected to be proportional to

448 approximately the square of such parameter.

\section{5. Conclusions and future perspective}

450 A model for estimating the pressure drop and flow distribution across a solar collector with U-type

configuration in isothermal conditions was developed. The pressure drops calculated by the model were compared to measurements carried out on a solar collector. The flow distributions were compared to previous literature findings.

454 For pressure drops higher than $1 \mathrm{kPa}$, all relative differences between model and measurements were within $\pm 7 \%$, apart from one point. For lower pressure drops the relative difference increased, but always within the accuracy of the differential pressure sensor.

457 Flow rate and viscosity were the main factors influencing the pressure drop, so different fluids having similar values for these two parameters gave almost identical pressure drops.

459 The flow distribution was mainly affected by the flow regime in the manifolds. Turbulent regime throughout the manifolds entailed a more uniform flow distribution compared to laminar flow. This was mainly due to the strong dependence of the local losses for the tee junctions in laminar conditions. The comparison between calculated flow distributions and results from literature gave a good agreement in most of the cases.

463 The presented model is planned to be used for the development of a numerical model for evaluating the flow distribution in large solar collector fields for district heating applications. In fact, flow rate and temperature levels in such fields vary depending of several boundary conditions, such as solar irradiance, fluid type, forward and return temperatures of the district heating network. Moreover, due to the temperature rise across a collector row, each collector experiences a different mean fluid temperature. In order to evaluate the flow distribution across the collector field, a flexible and accurate model is needed to calculate the pressure drop across each collector in different operating conditions.

470 Additionally, regarding the flow distribution, the model can be used to optimize the design of collector.

471 Aspects which may be investigated are the ratio between manifold diameter and absorber pipe diameter, 472 length of the absorber pipes and effect of pipe inset into the manifold. The results could be used by collector 
manufacturers to design their products in such a way that a more uniform flow distribution is achieved under typical operation, and thereby improve the collector efficiency.

475

476

477

478

479

480

481

482

483

484

485

486

487

488

489

490

491

492

493

494

495

496

497

498

499

500

501

502

503

504

505

506

507

508

509

510

511

512

513

514

\section{Acknowledgements}

The authors are thankful to the Marie-Curie Actions - Initial Training Network research programme of the European Union which supported the first author through the SolNet-SHINE project. The authors are also grateful to the company Arcon-Sunmark A/S for having made available the HT-SA collector used during the study.

\section{References}

Bava, F., 2015. https://github.com/febav/CollectorPressureDrop.git, accessed on 09/01/2016

Binder, R.C., 1973. Fluid Mechanics, fifth ed. Prentice Hall, Englewood Cliffs, USA.

Chiou, J.P., 1982. The effect of non-uniform fluid flow distribution on the thermal performance of solar collector. Solar Energy 29(6), 487-502.

Colebrook, C.F., 1939. Turbulent flow in pipes, with particular reference to the transition region between smooth and rough pipe laws. Journal of the Institution of Civil Engineers 11, 133-156.

Fan, J., Shah, L.J., Furbo, S., 2007. Flow distribution in a solar collector panel with horizontally inclined absorber strips. Solar Energy 81(12), 1501-1511.

Furbo, S., 2015. Using water for heat storage in thermal energy storage (tes) systems, in: Cabeza, L.C. (Ed.), Advances in Thermal Energy Storage Systems. Woodhead Publishing-Elsevier, Cambridge, United Kingdom, pp. 31-47.

Haaland, S.E., 1983. Simple and Explicit Formulas for the Friction Factor in Turbulent Flow. Journal of Fluids Engineering (ASME) 105(1), 89-90.

Holman, J.P., 2002. Heat transfer, ninth ed. McGraw-Hill, New York, USA.

Idelchik, I.E., 1994. Handbook of hydraulic resistance, third ed. CRC press, Boca Raton, USA.

ISO Standard 9806, 2014. Solar energy - Solar thermal collectors - Test methods. International Organization for Standardization (ISO), Geneva, Switzerland.

Jones, G.F., Lior, N., 1994. Flow distribution in manifolded solar collectors with negligible buoyancy effects. Solar Energy 52(3), 289-300.

Jones, G. F. and Lior, N., 1987. Conjugate heat transfer and flow distribution in an assembly of manifolded finned tubes, in: Kitto, J. B. Jr. and Robertson, J. M. (Eds.), Maldistribution of flow and its effect on heat exchanger performance, ASME HTD 75, pp. 127-136.

Joseph, D.D., Yang B.H., 2010. Friction factor correlations for laminar, transition and turbulent flow in smooth pipes. Physica D 239, 1318-1328.

Kestin, J., Sokolov, M., Wakeham, W.A., 1978. Viscosity of liquid water in the range $-8{ }^{\circ} \mathrm{C}$ to $150^{\circ} \mathrm{C}$. Journal of Physical and Chemical Reference Data 7, 941-948.

Kovacs, P., Persson, M., Wahlgren, P., Jensen, S., 2012. Quality assurance in solar thermal heating and cooling technology - Pressure drop over a solar flat plate collector using various heat transfer fluids. Deliverable D2.2 - R2.13 of Project IEE/08/593/SI2.529236. [Available online at http://www.estif.org/, accessed on 18/12/2015]

Miller D. S., 2009. Internal Flow Systems, second ed. Miller Innovations, Bedford, United Kingdom.

Ohnewein, P., Hausner, R., Preiß, D., 2015. Hydraulikdesign von parallelen Kollektormodulen in solarthermischen Großanlagen. Neue Energien 2020 - ParaSol project. [Available online at http://www.solarthermalworld.org/keyword/parasol, accessed on 05/04/2016] 
515 Wang, X.A., Wu, L.G., 1990. Analysis and performance of flat plate solar collector arrays. Solar Energy 516 45(2), 71-78.

517 Weitbrecht, V., Lehmann, D., Richter, A., 2002. Flow distribution in solar collectors with laminar flow 518 conditions. Solar Energy 73(6), 433-441.

519 Windeleff, J., Nielsen, J.E., 2014. Solar District Heating in Denmark. Danish Energy Agency and 520 PlanEnergi.

\section{Appendix}

522 To evaluate the Reynolds number at which transition in flow regime occurred, the following procedure was

523 followed. The pressure drop across the collector was measured while varying gradually the fluid inlet

524 temperature and keeping a constant flow rate. The test was performed in cloudy sky conditions, so that the

525 inlet and outlet temperature were approximately the same. Due to non-uniform flow distribution, the

526 different absorber pipes had different flow rates. Using the presented numerical model, it was possible to

527 identify the pipe having a value of flow rate closer to the flow rate which would occur in case of perfectly

528 uniform flow distribution. For the selected pipe, the numerical model was also used to isolate the pressure

529 drop caused by the absorber pipe from that caused by the manifolds and tee junctions. The Darcy friction

530 factor was finally calculated through (eq.1), using the pipe pressure drop and a fluid velocity corresponding

531 to a perfectly uniform flow distribution.

532 The comparison between the so calculated Darcy friction factor and the theoretical one is shown in Figure

533 A1. In the diagram the curved referred to as "theoretical" friction factor is obtained from (eq.7) for $R e<2300$,

534 from (eq.8) for $R e>3100$ and from linear interpolation between the two for the intermediate Reynolds

535 numbers. The data points refer to the results of a test performed with a $42 \%$ glycol/water mixture, a total

536 flow rate of $1.98 \mathrm{~m}^{3} / \mathrm{h}$ and a mean fluid temperature increasing from $30{ }^{\circ} \mathrm{C}$ to $70{ }^{\circ} \mathrm{C}$ during 2.5 hours.

537 Figure A1: Comparison between theoretical and calculated Darcy friction factor. The theoretical friction factor curve is obtained

538 from (eq.7) for $R e<2300$, (eq.8) for $R e>3100$ and linear interpolation between the two in between these values. 